\title{
Synthesis of Biphasic Calcium Phosphate and its Behaviour in Simulated Body Fluid
}

\author{
X. V. BÙ I ${ }^{1,2^{*}}$ AND T. D. THẮNG ${ }^{1}$
}

\begin{abstract}
The main goal of this study is to elaborate and evaluate the physicochemical properties of the synthetic biphasic calcium phosphate (BCP) powder: an associate compound of hydroxyapatite (HA): $\mathrm{Ca}_{10}\left(\mathrm{PO}_{4}\right)_{6}(\mathrm{OH})_{2}$ and beta-tricalcium phosphate $(\beta-\mathrm{TCP}): \mathrm{Ca}_{3}\left(\mathrm{PO}_{4}\right)_{2}$. The new compound $\mathrm{BCP}$ has two advantages: high bioactivity (HA) and fast biodegradation ( $\beta$-TCP). The obtained powder of BCP was prepared by the precipitate method. XRD analysis confirmed the synthetic material contained both HA and $\beta$-TCP crystalline phases. SEM images showed that the small particles of HA attached to bigger particles of $\beta-\mathrm{TCP}$ in the structure morphology of $\mathrm{BCP}$. The in vitro experiment was carried out in static condition by soaking of a series of $50 \mathrm{mg} \mathrm{BCP}$ powder in $100 \mathrm{ml}$ of simulated body fluid solution at different period of soaking time. The XRD and SEM methods studied the microstructure and chemical bond after soaking. The obtained results confirmed the bioactivity of synthetic BCP material by the formation of a new apatite layer on its surface.
\end{abstract}

Key words: High bioactivity; beta-tricalcium phosphate; biphasic calcium phosphate; bioactivity; simulated body fluid

Hydroxyapatite $\left[\mathrm{Ca}_{10}\left(\mathrm{PO}_{4}\right)_{6}(\mathrm{OH})_{2}, \mathrm{HA}\right]$ is commonly used as bioactive materials in bone graft, orthopaedic application, dental implant etc. since its unique ability to bond to bone after implantation (Ellinge et al. 1986). The ability of bond to bone can be predicted by its capacity to form HA layer on the surface upon immersed in simulated body fluid (SBF) solution, of which the ion concentrations is similar to human plasma (Nery et al. 1990). SBF screening is commonly used to predict the ability to bond to bone since its simplicity and economic, before implant into a live animal.
In the other hand, the $\beta$-tricalcium phosphate $\left[\beta-\mathrm{Ca}_{3}\left(\mathrm{PO}_{4}\right)_{2}, \beta-\mathrm{TCP}\right]$ is known as biodegradable materials, but exposes its weak bioactivity (Petrov et al. 2001). So if we can combine HA and $\beta$-TCP with proper ration, we are also possible to control the advantage of biphasic calcium phosphate (BCP): high bioactivity and its fast biodegradation (Victoria \& Gnanam 2002; Aslanidou et al. 2012).

In this research, we aim to synthesize the BCP powder by the wet chemical precipitation method and evaluate the physicochemical properties of the synthetic material before and after in vitro test in SBF.

\footnotetext{
${ }^{1}$ Ton Duc Thang University, No. 19 Nguyen Huu Tho Street, Tan Phong Ward, District 7, Ho Chi Minh City, Viet Nam

${ }^{2}$ Ho Chi Minh City Industry and Trade College, No. 20 Tang Nhon Phu Street, Phuoc Long B Ward, District 9, Ho Chi Minh City, Viet Nam

* Corresponding author (e-mail: buixuanvuong@tdt.edu.vn)
} 


\section{MATERIALS AND METHODS}

\section{Preparation of BCP Powder}

$\mathrm{BCP}$ is prepared similar to the research of Nezahat Kivrak with the weight ratio of HA and $\beta$-TCP is $20 / 80$ (Kivrak \& Cuneyt Tas 1998). At first, $\left(\mathrm{NH}_{4}\right)_{2} \mathrm{HPO}_{4} 0.1128 \mathrm{M}$ was dropped into $\mathrm{Ca}\left(\mathrm{NO}_{3}\right)_{2} \cdot 4 \mathrm{H}_{2} \mathrm{O} 0.4 \mathrm{M}$ so that the weight ratio of $\mathrm{HA} / \beta$-TCP is $20 / 80$. The dropping rate was approximately at $3 \mathrm{ml} / \mathrm{min}$, and chemical reaction was maintained at $40^{\circ} \mathrm{C}$, then adding $\mathrm{NH}_{4} \mathrm{OH} 0.1 \mathrm{M}$ to adjust $\mathrm{pH}=8$. After finishing, it was filtered many times by distilled water to remove the bad smell of $\mathrm{NH}_{4} \mathrm{OH}$ solution. Then the aqueous suspension was transferred into the oven and dried at $120^{\circ} \mathrm{C}$ for $8 \mathrm{~h}$ to obtain the powder, following the calcination at $1000^{\circ} \mathrm{C}$ for $5 \mathrm{~h}$. The synthetic flowchart is presented in Figure 1.

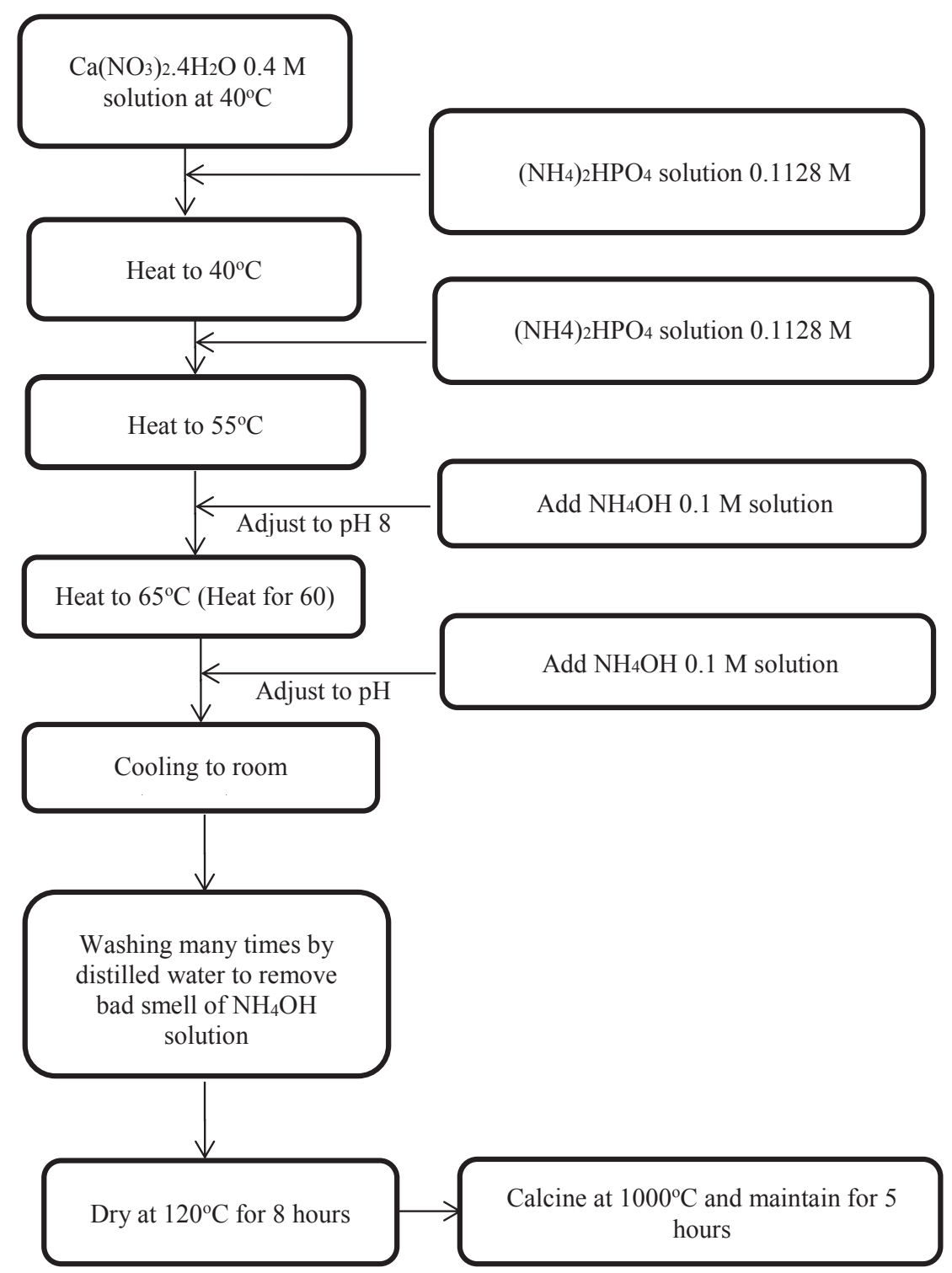

Figure 1. Synthetic process of BCP powder. 


\section{In vitro Experiment}

To predict the bond to the bone ability of $\mathrm{BCP}$, we soaked BCP powder in the SBF solution. The ion composition of SBF solution is similar to human plasma. SBF solution was prepared by $\mathrm{NaCl}$, $\mathrm{NaHCO}_{3}, \mathrm{KCl}, \mathrm{K}_{2} \mathrm{HPO}_{4} \cdot 3 \mathrm{H}_{2} \mathrm{O}, \mathrm{MgCl}_{2} \cdot 6 \mathrm{H}_{2} \mathrm{O}$ and $\mathrm{C}_{\mathrm{a}} \mathrm{Cl}_{2}$. They are dissolved in distilled water and buffered with $\left(\mathrm{CH}_{2} \mathrm{OH}\right)_{3} \mathrm{CNH}_{2}$ and $\mathrm{HCl}(6 \mathrm{~N})$ to adjust the $\mathrm{pH}$ value at 7.4. This process is according to the Kokubo's method (Kokubo \& Takadama 2006). The ratio (50 $\mathrm{mg}$ of material in $100 \mathrm{ml}$ of SBF solution) was chosen in in vitro experiment.

\section{Characterization of BCP Powder}

To characterize physicochemical properties of biomaterial before and after soaking in SBF solution, some analysis of physico-chemical methods were used like X-ray diffractometer (XRD) and scanning electron microscopy (SEM). To evaluate the crystalline phase, constitution and component of BCP, XRD (Bruker D8 Advance) were employed. The XRD performed with a scan speed of $0.02 \% \mathrm{~min}$ and step time was $1 \mathrm{~s} / \mathrm{min}$. XRD data were acquired in the range of $2 \theta$ from $5^{\circ}$ to $65^{\circ}$. SEM (Hitachi, Joel 5) was used to observe and evaluate the morphology of material before and after soaking in SBF solution, and determine the formation of the new apatite layer after soaking in SBF solution.

\section{RESULT AND DISCUSSION}

\section{Characterization of Synthetic BCP Material}

Figure 2 shows XRD patterns of synthetic $\mathrm{BCP}$ with HA standard and $\beta$-TCP standard. The synthetic BCP had specific peaks of both HA and $\beta$-TCP and had not stranger peaks (Pramanik et al. 2007; Biqin et al. 2008; Mir et al. 2012). XRD pattern of BCP had the sharp peaks which showed that $\mathrm{BCP}$ had an excellent crystallinity. The obtained result confirmed that the synthetic BCP was a combination of two phases: HA and $\beta$-TCP and of complete purity.

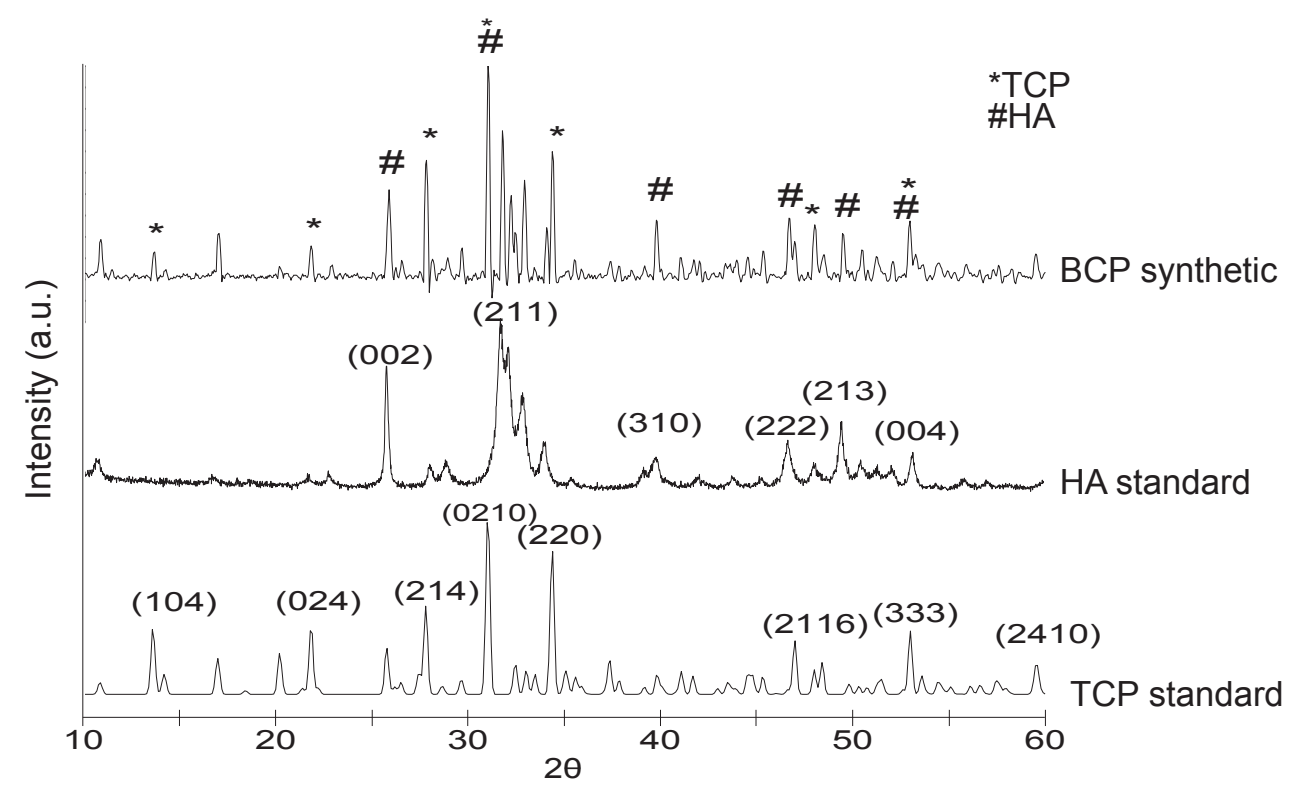

Figure 2. XRD patterns of synthetic BCP with HA standard and $\beta$-TCP standard. 
Figure 3 shows SEM images of $\beta$-TCP, $\mathrm{HA}$, and BCP. The SEM micrograph showed two phase of HA and $\beta$-TCP with HA phase was the small particles that attached to bigger particles of $\beta$-TCP. This result confirmed the combination of HA and $\beta$-TCP in the structure of BCP.

\section{In vitro test}

Figure 4 regroups the XRD patterns of $\mathrm{BCP}$ after $0,1,5$ and 10 days of soaking in SBF solution. After 1 day of soaking in SBF, there was a significant change before soaking. The $\beta$-TCP phase in BCP had crystallized while the HA phase had decomposed. But from 5 to 10 days the process carried out reversely. The HA phase had crystallized, and the $\beta$-TCP phase had decomposition. These phenomena confirmed the chemical interactions between BCP and $\mathrm{SBF}$ medium to conduit a new apatite layer on its surface. After a long time of soaking, $\beta$-TCP phase in BCP would have been completely decomposed and replaced by a new apatite layer.

Figure 5 shows SEM micrographs of $\mathrm{BCP}$ after $0,1,5$ and 10 days of soaking in SBF solution. After one day of soaking, no phenomena appeared. After five days of soaking, a thin layer was coated on BCP surface like grass. After ten days, the new layer continued to develop. This confirmed the bioactivity of synthetic material.
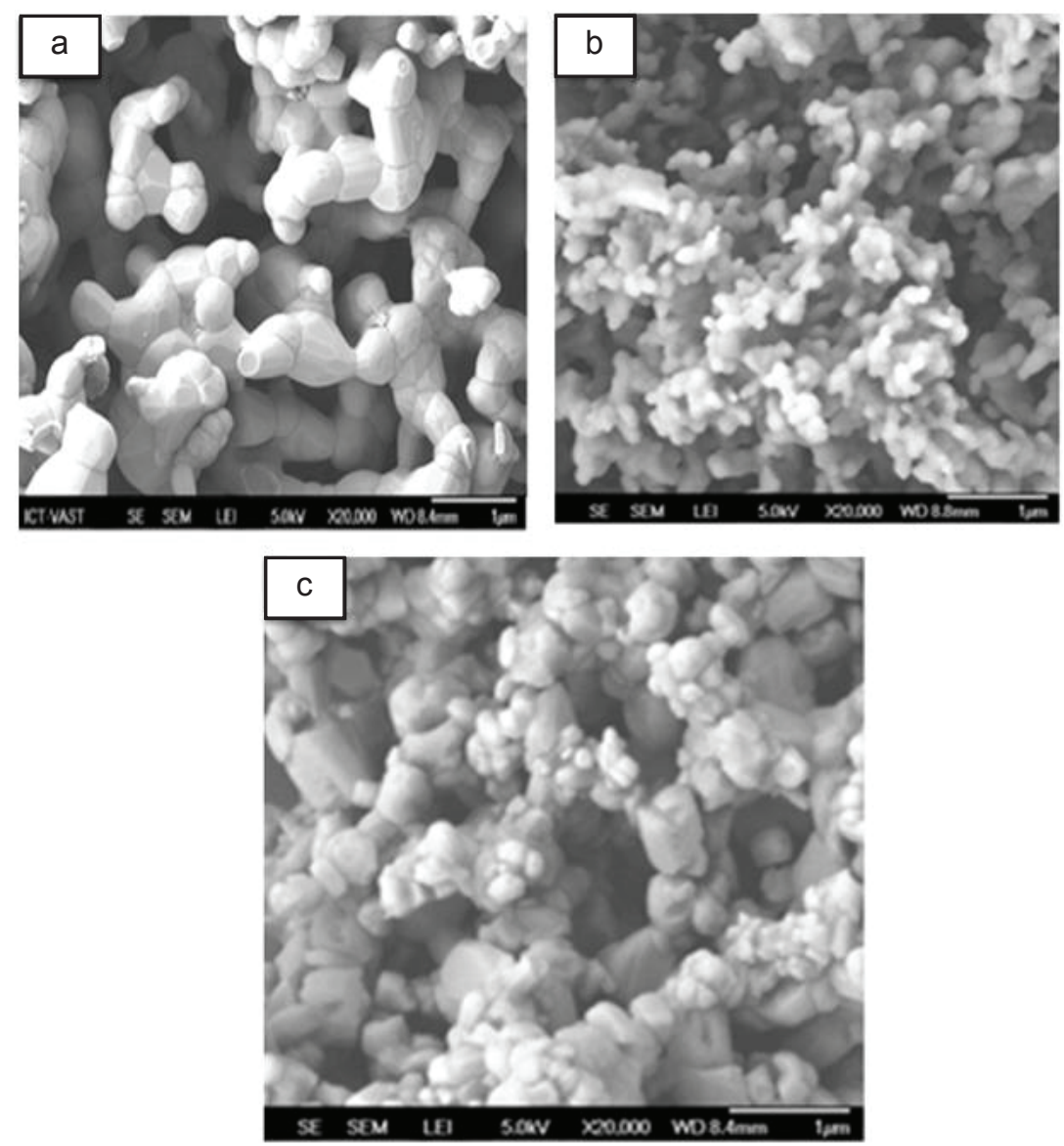

Figure 3. SEM images of (a) $\beta$-TCP, (b) HA and (c) BCP. 


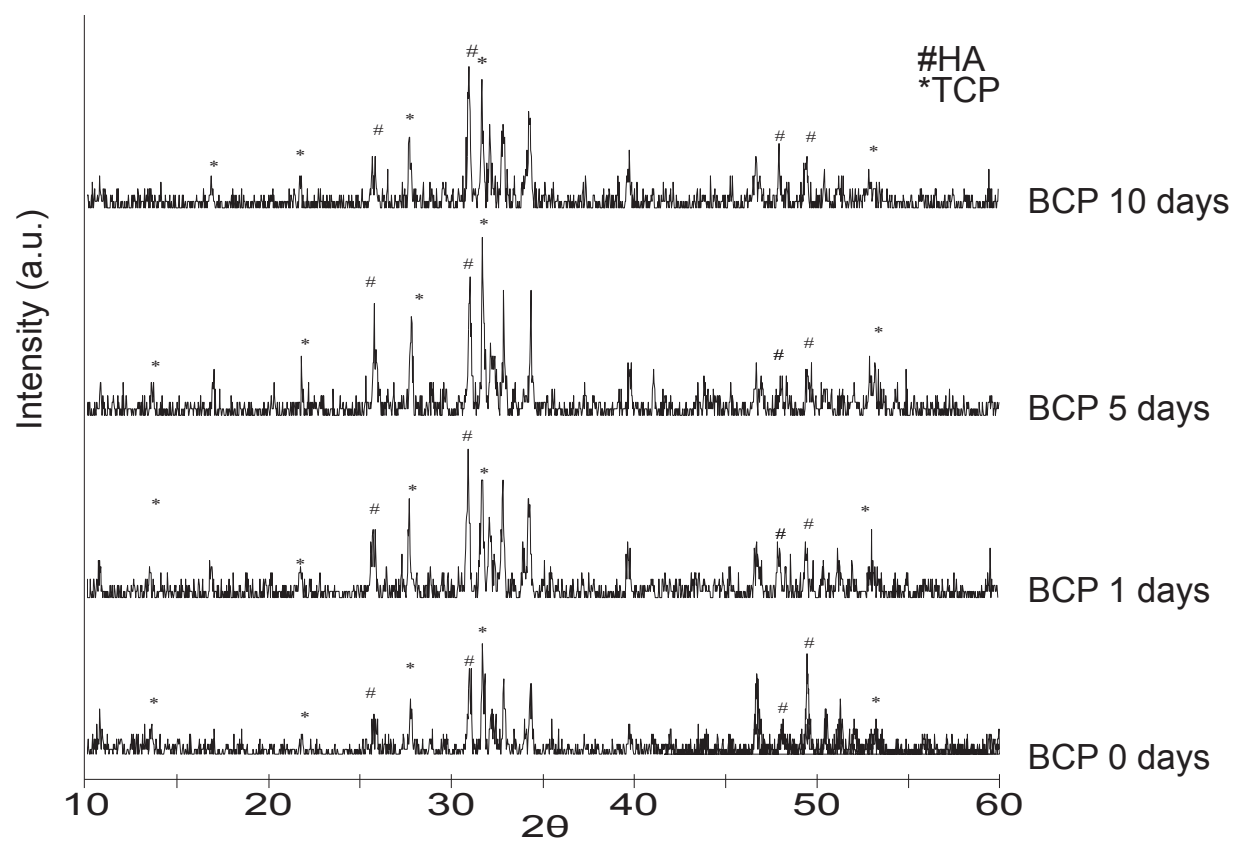

Figure 4. XRD patterns of BCP after 0, 1, 5 and 10 days of soaking in SBF solution.
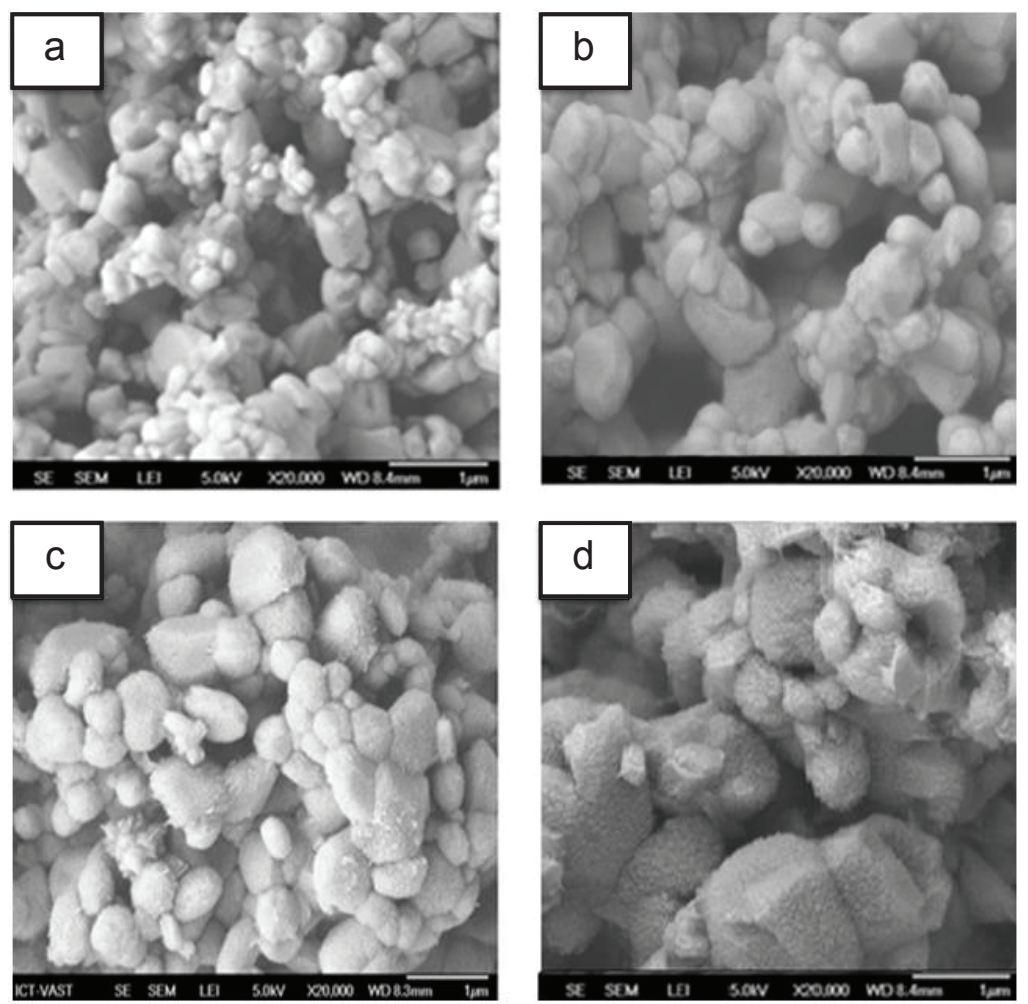

Figure 5. SEM micrograph of BCP after (a) 0, (b) 1, (c) 5 and (d) 10 days of soaking in SBF solution. 


\section{CONCLUSIONS}

Our research group succeeded to synthesise $\mathrm{BCP}$ powder via wet chemical precipitate method. Physicochemical characterization by $\mathrm{XRD}$ and FTIR confirmed the presence of two phases HA and $\beta$-TCP.

In vitro test to evaluate the bioactivity was carried out in the SBF solution. XRD and SEM analyses showed that the formation of a new apatite layer and the disappearance of $\beta$-TCP phase. This material could be used as biomaterials for bone replacement.

Date of submission: December 2016 Date of acceptance: January 2017

\section{REFERENCES}

Aslanidou, M, Vaimakis, T, Anastasios, M \& Trapalis, C 2012, 'A novel approach on the preparation of biphasic calcium phosphate bioceramics under physiological conditions. The effect of the starting material', ScieVerseScienceDirect, Ceramics International, nd.

Biqin, C, Zhaoquan, Z, Jingxian, Z, Qingling, L \& Dongliang, J 2008, 'Fabrication and mechanical properties of $\beta$-TCP pieces by gelcasting method', Mater. Sci. Eng. C., vol. 28, pp. 1052-1056.

Ellinger, RF, Nery, EB \& Lynch, KL 1986, J. Periodontol. Restor. Dent., vol. 3, pp. 1035-1038.
Kivrak, N \& Tas, AC 1998, 'Synthesis of calcium hydroxyapatite-tricalcium phosphate (HA-TCP) composite bioceramic powders and their sintering behavior', J. Am . Ceram. Soc., vol. 81, no. 9, pp. 2245-2252.

Kokubo, T \& Takadama, H 2006, 'How useful is SBF in predicting in vivo bone bioactivity?', Biomaterials., vol. 27, no. 14, pp. 2907-2915.

Nery, EB, Lee, KK \& Czajkowski, S et al. 1990, J. Periodontol., vol. 61, no. 12 , pp.737-744.

Petrov OE, Dyulgerova, E, Petrov, L \& Popova, R 2001, 'Characterisation of calcium phosphate phases obtained during the preparation of sintered biphasic Ca-P ceramics', Material letters, vol. 48, pp. $162-167$

Victoria, EC \& Gnanam, FD 2002, 'Synthesis and characterisation of biphasicalcium phosphate', Trends in Biomaterials and Artificial Organs, vol. 15, no. 1, pp. 12-14.

Pramanik, S, Agarwal, AK, Ra, KN \& Garg, A 2007, 'Development of high strength hydroxyapatite by solid-state-sintering process', Ceramics International, vol. 33, no. 3, pp. 419-426.

Mir, M, Leite, FL, Sérgio, PPH Jr., Pissetti, FL, Rossi, AM, Moreira, EL \& Mascarenhas, YP 2012, 'XRD, AFM, IR and TGA study of nanostructured hydroxyapatite', Mat. Res., vol. 15, no. 4. (E-pub July 03, 2012) 